\title{
Rapidly progressive cervical myelopathy had a high risk of developing deep venous thrombosis: a prospective observational study in 289 cases with degenerative cervical spine disease
}

\author{
Katsuhisa Yamada ${ }^{1,2} \cdot$ Kota Suda $^{1} \cdot$ Satoko Matsumoto Harmon ${ }^{1} \cdot$ Miki Komatsu $^{1} \cdot$ Chikara Ushiku $^{1}$. \\ Masahiko Takahata $\mathbb{( I D}^{2} \cdot$ Akio Minami $^{1} \cdot$ Norimasa Iwasaki $^{2}$
}

Received: 8 June 2018 / Revised: 28 August 2018 / Accepted: 15 October 2018 / Published online: 29 October 2018

(c) International Spinal Cord Society 2018

\begin{abstract}
Study design A prospective observational study.

Objectives To determine the incidence of deep venous thrombosis (DVT) and to evaluate the risk factors for DVT development associated with degenerative cervical spine disease.

Setting Hokkaido Spinal Cord Injury Center, Japan.

Methods Between April 2008 and March 2015, patients with degenerative cervical spine disease, such as compressive myelopathy or radiculopathy, who underwent surgical treatment were prospectively assessed. Leg vein ultrasonography and D-dimer tests were performed preoperatively and at 4 days after surgery. All patients received treatment with intermittent pneumatic compression and elastic stockings for primary DVT prophylaxis. No anticoagulation medications were used for DVT prophylaxis.

Results A total of 289 patients (203 males, 86 females; median age: 67 years (interquartile range, 58-76)) were included. Nine patients (3.1\%) exhibited DVT during the perioperative period. All 9 cases were women who had distal DVT. The incidences of preoperative and postoperative DVT were $1.1 \%$ and $2.1 \%$, respectively. The univariate analysis showed that statistically significant risk factors for perioperative DVT included female gender $(P<0.01)$, advanced age $(P=0.04)$, a low Japanese Orthopaedic Association score $(P=0.03)$, rapidly progressive myelopathy $(P<0.01)$, and inability to walk $(P=$ $0.01)$. The multivariate analysis showed that rapidly progressive myelopathy $(P=0.04)$ was the most important risk factor. Conclusion Female gender and rapidly progressive myelopathy are high-risk factors that predict the development of DVT during the perioperative period of cervical spine surgery. This result indicates that screening and treatment for DVT are needed in such high-risk patients.
\end{abstract}

\section{Introduction}

Deep venous thrombosis (DVT) is a potentially fatal complication because of the risk of pulmonary thromboembolism development $[1,2]$. Prevention, early detection, and timely treatment of DVT are very important during the perioperative period of spinal surgery [3]. According to

Katsuhisa Yamada

yka2q@yahoo.co.jp

1 Hokkaido Spinal Cord Injury Center, Bibai, Hokkaido, Japan

2 Department of Orthopaedic Surgery, Faculty of Medicine and Graduate School of Medicine, Hokkaido University,

Sapporo, Hokkaido, Japan various reports, the incidence of DVT in patients who undergo spinal surgery ranges from 0.3 to $31 \%$ [4-7]. The incidence of DVT has been reported to vary depending on the type of disease, spinal level, method of surveillance, DVT prophylaxis, and surveillance period [5, 8].

The incidence of DVT in the patients with cervical spinal cord injury due to trauma is very high particularly in those unable to walk and with severe paralysis of the lower limbs [3]. Because patients with cervical degenerative spinal disease often have paralysis of the lower limbs and walking disabilities, it is very important to evaluate the risk of DVT during the perioperative period of degenerative cervical spine surgery. Previous studies have reported that perioperative DVT was usually detected in the period between 3 and 7 days after spinal surgery [9, 10]. However, few reports have been published on perioperative DVT in 
patients with degenerative cervical spine disease without acute traumatic spinal cord injury, such as compressive myelopathy or radiculopathy. The purpose of this study is to elucidate the incidence and risk factors for perioperative DVT development by prospectively analyzing patients who underwent cervical spine surgery for degenerative spinal disease.

\section{Methods}

A total of 761 patients who underwent cervical spine surgery between April 2008 and March 2015 in the Hokkaido Spinal Cord Injury Center were enrolled in this study. The exclusion criteria consisted of spinal cord injury due to trauma, infection, inflammatory disease, neoplastic disease, and other diseases for which anticoagulation medication was prescribed. We obtained approval from the institutional review board of Hokkaido Spinal Cord Injury Center and written informed consent was attained from all patients prior to their enrollment.

Leg vein ultrasonography and D-dimer tests were performed preoperatively and at the median of 4 days (IQR: 4-5, mean: 4.1, standard deviation: 0.54) after surgery. Bilateral ultrasonography of both legs (SSD2000; ALOKA, Tokyo, Japan, Aplio XG; TOSHIBA, Tokyo, Japan) was performed by experienced physicians. When DVT was detected before and/or after surgery, a cardiovascular surgeon was consulted, and anticoagulant therapy was started using unfractionated heparin and/or warfarin.

Intermittent pneumatic compression with a calf pump and elastic stockings were used in all cases from induction of general anesthesia to postoperative ambulation. Patients were allowed to leave the bed using a wheelchair and begin walking the day after the operation. No anticoagulation medications were used for DVT prophylaxis.

The incidence of DVT was evaluated in relation to the following factors. There was a total of 12 predictors. The details are as follows:

Patient factors: (i) Gender (male or female with male as the reference). (ii) Age (years). (iii) Existence of diabetes mellitus (yes/no with no as reference). (iv) Existence of cardiovascular disease (yes/no with no as reference). Disease factors: (i) preoperative Japan Orthopaedic Association scoring system for the evaluation of cervical myelopathy (JOA score, 0-17 points) [11]. (ii) Preoperative motor score of the lower limbs (0-50 points) as per the International Standards for Neurological Classification of Spinal Cord Injury, in order to evaluate the risk factor for DVT development in relation to the paralysis of lower limbs [12]. (iii) Rapidly progression of myelopathy dichotomized (yes/no with no as reference). Rapidly progression of myelopathy was defined as patients with a JOA score that decreased two points or more during a recent 1-month period [13]. The patients' severity of myelopathy in a recent 1-month period was evaluated by clinical interview based on the course of neurological disorder (ability to walk, ability to go up and down stairs, worsening of fine motor skills (trouble with handwriting, manipulating buttons, or handling chopsticks)), and we evaluated the difference in JOA score between admission and 1 month before admission. (iv) Preoperative walking ability dichotomized according to the ability to walk with or without aids (inability to walk, yes/ no with no as reference). Walker (inability to walk: no) was defined as patients who can walk with or without walking aids. Surgery-related factors: (i) operating time (minutes). (ii) Intraoperative blood loss (ml). (iii) Surgical approach (posterior or anterior with anterior as reference). (iv) Spinal fusion (yes/no with no fusion as reference).

The results are expressed as the mean \pm standard deviation. Statistical analyses were performed using Fisher's exact probability test, the Mann-Whitney $U$, test and binomial logistic regression analysis, as appropriate. The multivariate analyses of the risk factors for perioperative DVT was performed in the following procedure. (1) Initial univariate analyses to quantify the association between the candidate predictors (a total of 10 predictors: gender, age, operating time, intraoperative blood loss, JOA score, lower extremity motor score, rapidly progressive myelopathy, inability to walk, diabetes mellitus, cardiovascular disease) and DVT. (2) Entering all predictors (except gender) and using a stepwise forward selection method to select a parsimonious set of predictors. (Gender was not appropriate for logistic analysis because of no male with DVT development.) (3) Testing the discrimination and calibration of the final set of predictors. Discrimination was measured with the use of the area under the receiver operating characteristic curve (AUC). We have evaluated calibration by calculating coefficient determination $\left(R^{2}\right)$. (4) Providing the odds ratio (OR) for the final set of predictors. When we have sampling zeros (i.e., zero counts), an ad hoc method to estimate the OR (modified OR) was used, which consisted of adding 0.5 to each cell value. A receiver operating characteristic (ROC) analysis was conducted to assess the D-dimer cutoff point. We considered a value of $P<0.05$ to be statistically significant throughout all analyses.

\section{Results}

Of the 761 patients, 289 patients who underwent cervical surgery for degenerative spinal disease met the inclusion criteria for this study (203 males, 86 females; median age: 67 years (interquartile range (IQR): 58-76)). The patients received spinal surgery for cervical spondylotic myelopathy $(n=197)$, cervical ossification of the posterior longitudinal 
Table 1 DVT in patients undergoing cervical spine surgery

\begin{tabular}{lllllll}
\hline Case & Age/gender & Diagnosis & Procedure & Positive DVT & DVT type & Location \\
\hline 1 & $55 / \mathrm{F}$ & C-OPLL & Laminoplasty & Pre-Op & Distal & Rt. Soleus v. \\
2 & $83 / \mathrm{F}$ & CSM & Posterior fusion & Pre-Op & Distal & Lt. Soleus v. \\
3 & $79 / \mathrm{F}$ & CSM & Posterior fusion & Pre-Op & Distal & Rt. Soleus v. \\
4 & $81 / \mathrm{F}$ & C-OPLL & Laminoplasty & POD 4 & Distal & Lt. Soleus v. \\
5 & $72 / \mathrm{F}$ & CSM & Laminectomy & POD 4 & Distal & Rt. Peroneal v. \\
6 & $89 / \mathrm{F}$ & CSM & Posterior fusion & POD 4 & Distal & Rt. Soleus v. \\
7 & $58 / \mathrm{F}$ & CDH & Anterior fusion & POD 4 (pre-op N/A) & Distal & Lt. Soleus v. \\
8 & $79 / \mathrm{F}$ & CSM & Posterior fusion & POD 4 (pre-op N/A) & Distal & Lt. Soleus v. \\
9 & $80 / F$ & CSM & Laminoplasty & POD 4 (pre-op N/A) & Distal & Rt. Peroneal v. \\
\hline
\end{tabular}

$D V T$ deep venous thrombosis, $C$-OPLL cervical ossification of posterior longitudinal ligament, $C S M$ cervical spondylotic myelopathy, $C D H$ cervical disc herniation, $\operatorname{Pre}-O p$ pre-operation, $P O D$ postoperative day, N/A not available, $R t$ right, $L t$ left, Soleus $v$. soleus vein, Peroneal $v$. peroneal vein ligament $(n=51)$, cervical disc herniation $(n=20)$, cervical spondylotic radiculopathy $(n=16)$, cervical kyphosis $(n=4)$, and cervical spondylosis $(n=1)$. Elective spine surgery was performed in 284 patients, and an emergency/sub-emergency operation was performed in 5 patients (4 cases: cervical spinal myelopathy, 1 case: cervical disc herniation).

The overall incidence of DVT was 3.1\% (9/289 cases) for cervical spine surgery patients (Table 1). All 9 cases of positive DVT were women who had distal DVT without proximal DVT. No patients had clinical signs of DVT. The incidence of preoperative DVT was $1.1 \%$ (3/284 cases, excluding 5 patients who were not examined because an emergency/sub-emergency operation was performed). The incidence of postoperative DVT was $2.1 \%$ (6/286 cases, excluding 3 cases of preoperative positive DVT). The length of bed rest after surgery was within $24 \mathrm{~h}$ in all patients.

The univariate analysis for preoperative DVT found that female gender was the only statistically significant risk factor $(P=0.024$, OR: $17.5,95 \%$ confidence interval $(\mathrm{CI})$ : 0.90-343.05) (Table 2). The risk factors related to the surgery, including the operation time, intraoperative blood loss, surgical approach, and spinal fusion, were not significantly associated with postoperative DVT in the univariate analysis (Table 3). The univariate analysis for perioperative DVT showed that statistically significant risk factors included female gender $(P<0.01$, OR: $49.9,95 \%$ CI: $2.87-867.5)$, advanced age $(P=0.04$, OR per 1 year increment: $1.08,95 \%$ CI: 1.00-1.16), low JOA score $(P=0.03$, OR: $0.03,95 \%$ CI: $0.57-0.97)$, rapidly progressive myelopathy $(P<0.01$, OR: $10.4,95 \%$ CI: $2.59-41.8)$ and inability to walk $(P=0.01$, OR: $6.5,95 \%$ CI: 1.51-28.0) (Table 4). As the results of stepwise forward selection, four variables (age, JOA score, rapidly progressive myelopathy, and inability to walk) were chosen as the final set of predictors for the multivariate analysis, and the AUC was 0.80 (95\% CI: $0.62-0.98)$ and the $R^{2}$ was
0.16. The multivariate analysis for perioperative DVT showed that rapidly progressive myelopathy $(P=0.04)$ was the only significant risk factor (Table 5).

No statistically significant difference was found between the DVT-positive group and the DVT-negative group in terms of the preoperative D-dimer level $(1.30 \pm 0.49$ vs. $0.93 \pm 1.22 \mu \mathrm{g} / \mathrm{ml})$. Patients with DVT had significantly higher D-dimer levels 4 days after surgery than those without DVT $(5.80 \pm 5.44$ vs. $1.82 \pm 1.22 \mu \mathrm{g} / \mathrm{ml} ; P<0.01)$. The cutoff D-dimer level determined from the ROC curve was $2.67 \mu \mathrm{g} / \mathrm{ml}$ on postoperative day 4 . The sensitivity was $83.3 \%$, and the specificity was $86 \%$.

\section{Discussion}

Thromboembolic events are potential complications of cervical spine surgery [7]. The incidence of DVT in patients who undergo cervical spine surgery has been reported to be $0.5-4.5 \%[5,7,14]$. However, the incidence of DVT development in patients who undergo cervical degenerative spinal surgery is controversial because previous studies have included patients with acute traumatic spinal cord injury, spinal tumors, rheumatoid arthritis, and infectious diseases $[5,7,14]$. The present study demonstrated that the perioperative incidence of DVT development in patients with degenerative cervical spine disease was $3.1 \%$.

The present study showed that patients with rapidly progressive myelopathy have a high risk of developing DVT in the multivariate analysis. Matsumoto et al. reported that the incidence of DVT is very high (36.8\%) in patients with cervical spinal cord injury due to trauma [3]. After acute traumatic spinal cord injury, severe paralysis can be accompanied by reduced venous return, leading to the development of DVT. Furthermore, because a possible loss of the circulatory variation in hemostatic and fibrinolytic function has also been suggested in patients with spinal cord injury due to trauma, DVT is quite likely to develop in the 
Table 2 Univariate analysis of the risk factors for preoperative DVT

Table 3 Univariate analysis of the risk factors for postoperative DVT

\begin{tabular}{|c|c|c|c|c|c|c|c|}
\hline \multirow{3}{*}{$\overline{\text { Gender, } n(\%)}$} & & & $\begin{array}{l}\text { DVT positive } \\
n=3\end{array}$ & $\begin{array}{l}\text { DVT } \\
\text { negative } \\
n=281\end{array}$ & $P$-value & $\begin{array}{l}\text { Odds } \\
\text { ratio }\end{array}$ & $95 \% \mathrm{CI}$ \\
\hline & \multicolumn{2}{|c|}{ Female } & $3(3.6 \%)$ & $80(96.4 \%)$ & 0.024 & $17.50^{\mathrm{a}}$ & $1.10-343.05$ \\
\hline & \multicolumn{2}{|c|}{ Male } & $0(0 \%)$ & $201(100 \%)$ & & 1.0 (ref.) & \\
\hline \multicolumn{3}{|c|}{$\begin{array}{l}\text { Age, median (IQR) } \\
\text { (years) }\end{array}$} & $79(67-81)$ & $67(58-76)$ & 0.42 & $1.05^{\mathrm{b}}$ & $0.94-1.17$ \\
\hline \multicolumn{3}{|c|}{$\begin{array}{l}\text { JOA score, mean } \pm \text { SD } \\
\text { (/17 points })\end{array}$} & $9.8 \pm 2.6$ & $10.0 \pm 2.6$ & 0.90 & 0.97 & $0.63-1.51$ \\
\hline \multicolumn{3}{|c|}{$\begin{array}{l}\text { Lower extremity motor } \\
\text { score, median (IQR) (/50 } \\
\text { points) }\end{array}$} & $50(48-50)$ & $49(46-50)$ & 0.50 & 1.16 & $0.76-1.78$ \\
\hline \multirow{2}{*}{\multicolumn{2}{|c|}{$\begin{array}{l}\text { Rapidly progressive } \\
\text { myelopathy, } n(\%)\end{array}$}} & + & $0(0 \%)$ & $20(100 \%)$ & 0.80 & $1.82^{\mathrm{a}}$ & $0.09-36.50$ \\
\hline & & - & $3(1.1 \%)$ & $261(98.9 \%)$ & & 1.0 (ref.) & \\
\hline \multirow{2}{*}{\multicolumn{2}{|c|}{$\begin{array}{l}\text { Inability to walk, } n \\
(\%)\end{array}$}} & + & $0(0 \%)$ & $20(100 \%)$ & 0.80 & $1.82^{\mathrm{a}}$ & $0.09-36.50$ \\
\hline & & - & $3(1.1 \%)$ & $261(98.9 \%)$ & & 1.0 (ref.) & \\
\hline \multirow{2}{*}{\multicolumn{2}{|c|}{$\begin{array}{l}\text { Diabetes mellitus, } n \\
(\%)\end{array}$}} & + & $0(0 \%)$ & $53(100 \%)$ & 0.54 & $0.61^{\mathrm{a}}$ & $0.03-12.00$ \\
\hline & & - & $3(1.3 \%)$ & $228(98.7 \%)$ & & 1.0 (ref.) & \\
\hline \multirow{2}{*}{\multicolumn{2}{|c|}{$\begin{array}{l}\text { Cardiovascular } \\
\text { disease, } n(\%)\end{array}$}} & + & $1(4.3 \%)$ & $22(95.7 \%)$ & 0.15 & 5.89 & $0.51-67.50$ \\
\hline & & - & $2(0.8 \%)$ & $259(99.2 \%)$ & & 1.0 (ref.) & \\
\hline
\end{tabular}

Gender: female was coded as 1 and male was coded as 0 . Rapidly progressive myelopathy, inability to walk, diabetes mellitus, and cardiovascular disease: yes was coded as 1 and no was coded as 0

$D V T$ deep venous thrombosis, $I Q R$ interquartile range, $S D$ standard deviation, JOA score Japanese Orthopaedic Association score, CI confidence interval, ref. reference

${ }^{a}$ Modified odds ratio

${ }^{\mathrm{b}}$ Odds ratio per 1 year increment

\begin{tabular}{|c|c|c|c|c|c|c|}
\hline & & $\begin{array}{l}\text { DVT positive } \\
n=6\end{array}$ & $\begin{array}{l}\text { DVT } \\
\text { negative } \\
n=280\end{array}$ & $P$-value & $\begin{array}{l}\text { Odds } \\
\text { ratio }\end{array}$ & $95 \% \mathrm{CI}$ \\
\hline \multicolumn{2}{|c|}{ Operating time, mean \pm SD (min) } & $102.8 \pm 55.7$ & $107.3 \pm 52.3$ & 0.42 & 1.10 & $1.00-1.21$ \\
\hline \multicolumn{2}{|c|}{$\begin{array}{l}\text { Intraoperative blood loss, mean } \pm \text { SD } \\
(\mathrm{ml})\end{array}$} & $39.5 \pm 42.6$ & $38.6 \pm 75.5$ & $0.49^{\mathrm{a}}$ & 1.00 & $0.98-1.01$ \\
\hline \multirow[t]{2}{*}{ Surgical approach, $n(\%)$} & Posterior & $5(1.9 \%)$ & $256(98.1 \%)$ & 0.50 & 0.47 & $0.05-4.18$ \\
\hline & Anterior & $1(4.0 \%)$ & $24(96.0 \%)$ & & 1.0 (ref) & \\
\hline \multirow[t]{2}{*}{ Spinal fusion, $n(\%)$} & + & $3(2.4 \%)$ & $123(97.6 \%)$ & 0.77 & 1.28 & $0.25-6.44$ \\
\hline & - & $3(1.9 \%)$ & $157(98.1 \%)$ & & 1.0 (ref) & \\
\hline
\end{tabular}

Surgical approach: posterior was coded as 1 and anterior was coded as 0 . Spinal fusion: yes was coded as 1 and no was coded as 0

$D V T$ deep venous thrombosis, $S D$ standard deviation, $C I$ confidence interval, ref. reference

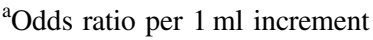

presence of acute traumatic spinal cord injury [3, 15]. Rapidly progressive myelopathy would cause sympathetic nerve disorder, which leads to reduced vascular contraction, like a spinal cord injury due to trauma. DVT is likely to develop in the presence of rapidly progressive myelopathy, even if paralysis is not severe.

Several risk factors have been reported for DVT development in patients undergoing spinal surgery, such as advanced age, female gender, obesity, neurological deficits, long operative time, and spinal tumors $[6,8,16,17]$. The present study showed that female gender, advanced age, rapidly progressive myelopathy, low JOA score, and inability to walk were statistically significant risk factors for perioperative DVT development associated with degenerative cervical spine disease. Concerning the pathogenesis of DVT, the three major factors in Virchow's triad (blood retention, capillary wall disorder, and blood coagulopathy) are well known $[3,15]$. Patients with a low JOA score have 
Table 4 Univariate analysis of the risk factors for perioperative DVT

\begin{tabular}{|c|c|c|c|c|c|c|}
\hline & & $\begin{array}{l}\text { DVT } \\
\text { positive } \\
n=9\end{array}$ & $\begin{array}{l}\text { DVT } \\
\text { negative } \\
n=280\end{array}$ & $P$-value & Odds ratio & $95 \% \mathrm{CI}$ \\
\hline \multirow[t]{2}{*}{ Gender, $n(\%)$} & Female & $9(10.5 \%)$ & $77(89.5 \%)$ & $<0.01$ & $49.9^{\mathrm{a}}$ & $2.87-867.50$ \\
\hline & Male & $0(0 \%)$ & $203(100 \%)$ & & 1.0 (ref.) & \\
\hline Age, median (IQR) (years) & & $79(72-81)$ & $67(58-76)$ & 0.04 & $1.08^{\mathrm{b}}$ & $1.00-1.16$ \\
\hline $\begin{array}{l}\text { Operating time, mean } \pm \mathrm{SD} \\
(\min )\end{array}$ & $\begin{array}{l}100.4 \pm \\
45.3\end{array}$ & $\begin{array}{l}107.3 \pm \\
52.3\end{array}$ & 0.70 & 0.10 & $0.98-1.01$ & \\
\hline \multicolumn{2}{|c|}{ Intraoperative blood loss, mean $\pm \mathrm{SD}(\mathrm{ml})$} & $38.6 \pm 35.2$ & $38.6 \pm 75.5$ & 1.0 & $1.00^{\mathrm{c}}$ & $0.99-1.01$ \\
\hline \multicolumn{2}{|c|}{ JOA score, mean \pm SD (/17 points) } & $8.1 \pm 2.9$ & $10.0 \pm 2.6$ & 0.03 & 0.74 & $0.57-0.97$ \\
\hline \multicolumn{2}{|c|}{$\begin{array}{l}\text { Lower extremity motor score, median } \\
\text { (IQR) (/50 points) }\end{array}$} & $49(40-50)$ & $49(45-50)$ & 0.53 & 0.97 & $0.88-1.07$ \\
\hline \multirow{2}{*}{$\begin{array}{l}\text { Rapidly progressive } \\
\text { myelopathy, } n(\%)\end{array}$} & + & $4(16.7 \%)$ & $20(83.3 \%)$ & $<0.01$ & 10.4 & $2.59-41.80$ \\
\hline & - & $5(1.9 \%)$ & $260(98.1 \%)$ & & 1.0 (ref.) & \\
\hline \multirow[t]{2}{*}{ Inability to walk, $n(\%)$} & + & $3(13.0 \%)$ & $20(87.0 \%)$ & 0.01 & 6.50 & $1.51-28.00$ \\
\hline & - & $6(2.3 \%)$ & $260(97.7 \%)$ & & 1.0 (ref.) & \\
\hline \multirow[t]{2}{*}{ Diabetes mellitus, $n(\%)$} & + & $3(5.5 \%)$ & $52(94.5 \%)$ & 0.28 & 2.19 & $0.53-9.05$ \\
\hline & - & $6(2.6 \%)$ & $228(97.4 \%)$ & & 1.0 (ref.) & \\
\hline \multirow{2}{*}{$\begin{array}{l}\text { Cardiovascular disease, } n \\
(\%)\end{array}$} & + & $2(8.7 \%)$ & $21(91.3 \%)$ & 0.13 & 3.52 & $0.69-18.00$ \\
\hline & - & $7(2.6 \%)$ & $259(97.4 \%)$ & & 1.0 (ref.) & \\
\hline
\end{tabular}

Gender: female was coded as 1 and male was coded as 0 . Rapidly progressive myelopathy, inability to walk, diabetes mellitus, and cardiovascular disease: yes was coded as 1 and no was coded as 0

$D V T$ deep vein thrombosis, $S D$ standard deviation, JOA score Japanese Orthopaedic Association score, $C I$ confidence interval, ref. reference

${ }^{a}$ Modified odds ratio

${ }^{\mathrm{b}}$ Odds ratio per 1 year increment

${ }^{c}$ Odds ratio per $1 \mathrm{ml}$ increment

\begin{tabular}{llllll}
\hline & $\begin{array}{l}\text { Partial regression } \\
\text { coefficient }\end{array}$ & Standard error & $P$-value & $\begin{array}{l}\text { Odds } \\
\text { ratio }\end{array}$ & $95 \%$ CI \\
\hline Age (years) & 0.06 & 0.04 & 0.13 & 1.06 & $0.98-1.15$ \\
JOA score (points) & -0.02 & 0.17 & 0.91 & 0.98 & $0.70-1.38$ \\
$\begin{array}{l}\text { Rapidly progressive } \\
\text { myelopathy }\end{array}$ & 1.92 & 0.94 & 0.04 & 6.85 & $1.09-43.24$ \\
$\begin{array}{l}\text { Inability to walk } \\
\text { Intercept }\end{array}$ & 0.40 & 1.04 & 0.70 & 1.49 & $0.19-11.51$ \\
\hline
\end{tabular}

$D V T$ deep vein thrombosis, JOA score Japanese Orthopaedic Association score, $C I$ confidence interval, ref. reference
Table 5 Multivariate analysis of the risk factors for perioperative DVT difficulty walking, leading to reduced venous return and blood retention. However, the current study demonstrated no significant difference between the DVT-positive group and the DVT-negative group for the motor score of the lower limbs. Even if the motor paralysis of the lower limbs was not severe, patients with myelopathy could not walk because of spasticity and disturbance of the posterior fasciculus of the spinal cord. These results suggest that walking ability is more important for DVT development than motor paralysis in patients with cervical spine disease.

Early detection of DVT in the perioperative period of spinal surgery is very important, however, little information is available regarding the timing of DVT onset, and the appropriate timing of DVT screening is controversial. In several reports, the peak onset of DVT is on day 4 after total joint arthroplasty, and the incidence of DVT significantly 
decreases on postoperative day 14 [9, 10]. Previous studies have reported that the first time when postoperative DVT may be detected occurs in the period between 3 and 7 days after spinal surgery $[3,8,18-20]$. Hence, we performed DVT screening using leg vein ultrasonography preoperatively and at 4 days after surgery. In this study, no patients exhibited fatal pulmonary thromboembolism development during the perioperative period.

There have been studies to show that the incidence of DVT is relatively lower in Asians including Japanese as compared to their Western counterparts [21-23]. Medical prophylaxis for DVT after total knee arthroplasty or total hip arthroplasty has been routinely performed in our hospital according to the Japanese guideline [24]. However, no anticoagulation medications have been used for DVT prophylaxis in spine surgery, because anticoagulation therapy was not recommended in patients undergoing spine surgery and those with spine injury in Japan [24]. This study showed that the prevalence of DVT in our patients underwent degenerative cervical spine surgery without chemoprophylaxis was $3.1 \%$. With risk assessment, proper surveillance, and a preventative protocol for DVT prophylaxis, routine medical prophylaxis may not be necessary in Japanese undergoing elective spine surgery.

D-dimer measurement is predominantly used for DVT screening because the diagnostic significance of the Ddimer test for predicting DVT is well known, however, the cutoff level of D-dimer for predicting the risk of developing DVT is controversial for spinal surgery. Matsumoto et al. set the D-dimer level cutoff point at $5.82 \mu \mathrm{g} / \mathrm{ml}$ on postoperative day 3 in patients with acute traumatic spinal cord injury who were treated surgically and reported that the sensitivity and specificity were $72.7 \%$ and $76.5 \%$, respectively [3]. Yoshioka et al. reported that the sensitivity and specificity of D-dimer measurements on day 7 after spinal surgery were $83.3 \%$ and $75.7 \%$, respectively, when the Ddimer cutoff level was set at $6.5 \mu \mathrm{g} / \mathrm{ml}$ [20]. A D-dimer level $>10 \mu \mathrm{g} / \mathrm{ml}$ is reported to be indicative of a high risk for DVT after total joint arthroplasty [25]. Yoshiiwa et al. set the D-dimer level cutoff point at $10 \mu \mathrm{g} / \mathrm{ml}$ and reported that $55 \%$ of patients whose D-dimer levels were over $10 \mu \mathrm{g} / \mathrm{ml}$ had DVT on day 4 after spinal surgery [19]. This study demonstrated that a D-dimer level cutoff of $2.67 \mu \mathrm{g} / \mathrm{ml}$ on postoperative day 4 provided $83.3 \%$ sensitivity and $86 \%$ specificity for degenerative cervical spine disease. Compared to previous reports $[3,19,20]$, the D-dimer cutoff point derived from our study was relatively low. One reason may be that these previous reports included patients with traumatic disease, infectious disease, spinal tumors, and inflammatory diseases $[3,19,20]$, which may be the reason that their D-dimer levels were high [26]. However, Hamidi et al. reported a similar result that the optimum D-dimer cutoff value was $2.1 \mu \mathrm{g} / \mathrm{ml}$ on day 3 following surgery in patients who underwent elective spinal surgery, excluding acute traumatic spinal cord injury and solid tumors [4]. Therefore, the D-dimer cutoff value of our study can be used as a reliable tool for DVT screening in cervical spine surgery cases.

There are several limitations in the present study. We did not perform ultrasonography for all patients before surgery. Four of the 5 patients did not receive preoperative DVT screening because they required an emergency operation because of rapidly progressive myelopathy. Among these patients, DVT was detected in 3 cases at 4 days after surgery, suggesting a possibility that DVT developed preoperatively. These data also suggest that rapidly progressive myelopathy is a crucial risk factor to predict the development of DVT. Another limitation is that the sample size was small compared to the frequency of DVT development to determine the risk factors, which caused wide $95 \% \mathrm{CI}$ in the analysis of several factors such as gender, rapidly progressive myelopathy, inability to walk, and cardiovascular disease. Because the number of DVT positive cases was very small, the sufficient sample size to determine the confident risk factors could be very large. This study showed possible risk factors for developing DVT in cervical spine surgery, however, the results could be one of the guidelines for DVT prophylaxis. Regarding statistical analysis, stepwise selection was used for entering variables into a multivariate logistic regression model. This procedure has a problem that variables which are causally related to outcome might be removed. As the results of stepwise forward selection, four variables (age, JOA score, rapidly progressive myelopathy, and inability to walk) were chosen as the final set of predictors for the multivariate analysis. However, initial univariate analysis showed that any other variables, except these four variables, were not significantly risk factors for DVT development. Advanced age, neurological deficit, and walking disability have been reported to be identified as important risk factors for DVT [6, 8, 14, 17]. Matsumoto et al. reported that traumatic spinal cord injury, which causes acute myelopathy, is also an important risk factor for DVT developing [3]. For these reasons, four variables (age, JOA score, rapidly progressive myelopathy, and inability to walk) could be appropriate as the final set of predictors for the multivariate analysis.

\section{Conclusion}

DVT assessment using ultrasonography and a D-dimer test is important for early detection and timely treatment of DVT during the perioperative period of cervical spine surgery. Multivariate analysis showed that rapidly progressive myelopathy is a high-risk factor for the perioperative development of DVT in patients with cervical spine 
surgery. Especially, elderly females with rapidly progressive cervical myelopathy have a high risk of developing DVT.

Author contributions Conception and design of the study: KS. Analysis and interpretation of data: KY and KS. Collection and assembly of data: KY, KS, SMH, MK, and CU. Drafting of the article: KY. Resource: KS and MK. Supervision: MT, AM, and NI. All authors read and approved the final manuscript.

\section{Compliance with ethical standards}

Conflict of interest The authors declare that they have no conflict of interest.

\section{References}

1. Freedman KB, Brookenthal KR, Fitzgerald RH Jr, Williams S, Lonner JH. A meta-analysis of thromboembolic prophylaxis following elective total hip arthroplasty. J Bone Jt Surg Am. 2000;82-A:929-38.

2. Zhou X, Qian W, Li J, Zhang P, Yang Z, Chen W, et al. Who are at risk for thromboembolism after arthroplasty? A systematic review and meta-analysis. Thromb Res. 2013;132:531-6.

3. Matsumoto S, Suda K, Iimoto S, Yasui K, Komatsu M, Ushiku C, et al. Prospective study of deep vein thrombosis in patients with spinal cord injury not receiving anticoagulant therapy. Spinal Cord. 2015;53:306-9.

4. Hamidi S, Riazi M. Cutoff values of plasma d-dimer level in patients with diagnosis of the venous thromboembolism after elective spinal surgery. Asian Spine J. 2015;9:232-8.

5. Glotzbecker MP, Bono CM, Wood KB, Harris MB. Thromboembolic disease in spinal surgery: a systematic review. Spine. 2009;34:291-303.

6. Yoshioka K, Murakami H, Demura S, Kato S, Tsuchiya H. Prevalence and risk factors for development of venous thromboembolism after degenerative spinal surgery. Spine. 2015;40:E301-6.

7. Oglesby M, Fineberg SJ, Patel AA, Pelton MA, Singh K. The incidence and mortality of thromboembolic events in cervical spine surgery. Spine. 2013;38:E521-7.

8. Akeda K, Matsunaga H, Imanishi T, Hasegawa M, Sakakibara T, Kasai $\mathrm{Y}$, et al. Prevalence and countermeasures for venous thromboembolic diseases associated with spinal surgery: a followup study of an institutional protocol in 209 patients. Spine. 2014;39:791-7.

9. Sikorski JM, Hampson WG, Staddon GE. The natural history and aetiology of deep vein thrombosis after total hip replacement. J Bone Jt Surg Br. 1981;63-B:171-7.

10. Yamaguchi T, Hasegawa M, Niimi R, Sudo A. Incidence and time course of asymptomatic deep vein thrombosis with fondaparinux in patients undergoing total joint arthroplasty. Thromb Res. 2010;126:e323-6.

11. Masaki Y, Yamazaki M, Okawa A, Aramomi M, Hashimoto M, Koda M, et al. An analysis of factors causing poor surgical outcome in patients with cervical myelopathy due to ossification of the posterior longitudinal ligament: anterior decompression with spinal fusion versus laminoplasty. J Spinal Disord Tech. 2007;20:7-13.

12. Maynard FM Jr, Bracken MB, Creasey G, Ditunno JF Jr, Donovan WH, Ducker TB, et al. International standards for neurological and functional classification of spinal cord injury. American Spinal Injury Association. Spinal Cord. 1997;3:266-74.

13. Sakuma T, Yamazaki M, Okawa A, Takahashi H, Kato K, Hashimoto $\mathrm{M}$, et al. Neuroprotective therapy using granulocyte colony-stimulating factor for patients with worsening symptoms of compression myelopathy, Part 1: a phase I and IIa clinical trial. Eur Spine J. 2012;21:482-9.

14. Oda T, Fuji T, Kato Y, Fujita S, Kanemitsu N. Deep venous thrombosis after posterior spinal surgery. Spine. 2000;25:2962-7.

15. Furlan JC, Fehlings MG. Cardiovascular complications after acute spinal cord injury: pathophysiology, diagnosis, and management. Neurosurg Focus. 2008;25:E13.

16. Schoenfeld AJ, Herzog JP, Dunn JC, Bader JO, Belmont PJ Jr. Patient-based and surgical characteristics associated with the acute development of deep venous thrombosis and pulmonary embolism after spine surgery. Spine. 2013;38:1892-8.

17. Tominaga H, Setoguchi T, Tanabe F, Kawamura I, Tsuneyoshi Y, Kawabata N, et al. Risk factors for venous thromboembolism after spine surgery. Medicine (Baltimore). 2015;94:e466.

18. Takahashi H, Yokoyama Y, Iida Y, Terashima F, Hasegawa K, Saito $\mathrm{T}$, et al. Incidence of venous thromboembolism after spine surgery. J Orthop Sci. 2012;17:114-7.

19. Yoshiiwa T, Miyazaki M, Takita C, Itonaga I, Tsumura H. Analysis of measured D-dimer levels for detection of deep venous thrombosis and pulmonary embolism after spinal surgery. J Spinal Disord Tech. 2011;24:E35-9.

20. Yoshioka K, Kitajima I, Kabata T, Tani M, Kawahara N, Murakami $\mathrm{H}$, et al. Venous thromboembolism after spine surgery: changes of the fibrin monomer complex and D-dimer level during the perioperative period. J Neurosurg Spine. 2010;13:594-9.

21. Yeo DX, Junnarkar S, Balasubramaniam S, Tan YP, Low JK, Woon $\mathrm{W}$, et al. Incidence of venous thromboembolism and its pharmacological prophylaxis in Asian general surgery patients: a systematic review. World J Surg. 2015;39:150-7.

22. Bin Abd Razak HR, Binte Abd Razak NF, Tan HA. Prevalence of venous thromboembolic events is low in Asians after total knee arthroplasty without chemoprophylaxis. J Arthroplasty. 2017;32:974-9.

23. Kanchanabat B, Stapanavatr W, Meknavin S, Soorapanth C, Sumanasrethakul C, Kanchanasuttirak P. Systematic review and meta-analysis on the rate of postoperative venous thromboembolism in orthopaedic surgery in Asian patients without thromboprophylaxis. Br J Surg. 2011;98:1356-64.

24. JCS Joint Working Group. Guidelines for the diagnosis, treatment and prevention of pulmonary thromboembolism and deep vein thrombosis (JCS 2009). Circ J. 2011;75:1258-81.

25. Shiota N, Sato T, Nishida K, Matsuo M, Takahara Y, Mitani S, et al. Changes in LPIA D-dimer levels after total hip or knee arthroplasty relevant to deep-vein thrombosis diagnosed by bilateral ascending venography. J Orthop Sci. 2002;7:444-50.

26. Raimondi $\mathrm{P}$, Bongard $\mathrm{O}$, de Moerloose $\mathrm{P}$, Reber G, Waldvogel F, Bounameaux H. D-dimer plasma concentration in various clinical conditions: implication for the use of this test in the diagnostic approach of venous thromboembolism. Thromb Res. 1993;69:125-30. 